
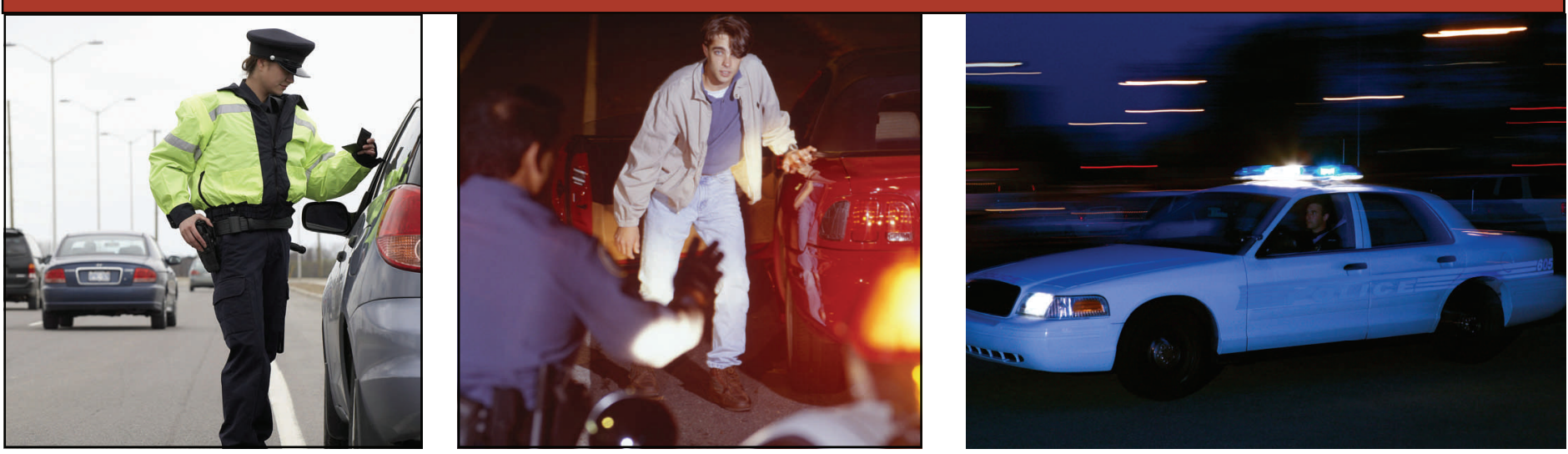

\title{
Safety and Health in Law Enforcement
}

\section{Advancing priorities through partnerships and research}

\section{NORA}

The National Occupational Research Agenda (NORA) is a partnership program to stimulate innovative research and improve workplace practices. Unveiled in 1996, NORA has become a framework for guiding occupational safety and health research in the nation. Diverse stakeholders collaborate to identify the most critical issues in the workplace, and work together to develop goals, objectives, and an implementation plan for addressing these issues. Law enforcement agencies, professional associations, labor unions, research organizations, and government agencies are encouraged to build partnerships to help reduce the risk of occupational injury and illness among law enforcement personnel.

\section{Who Works in Law Enforcement?}

Across the United States, law enforcement agencies employ more than 800,000 workers. Approximately 624,500 of these workers are employed as police and sheriff patrol officers. Approximately $89 \%$ of these officers are employed by local agencies and about $9 \%$ are employed by state law enforcement agencies as reported by the U.S. Bureau of Labor Statistics [www.bls.gov/oes/current/oessrci.htm\#99, May 2009 estimates accessed November 9, 2010]. Individuals working in law enforcement include:

- Police Officers

- Sheriff Patrols

- Detectives \& Investigators

- Police Dispatchers
- Crime Lab Personnel

- Court Bailiffs

- Administrative Staff

\section{What are the Important Safety \& Health Issues for Law Enforcement?}

The leading causes of occupational fatalities among police officers was highway incidents and homicides with 81 being reported in 2009 by the U.S. Bureau of Labor Statistics [www.bls.gov/ iif/oshwc/cfoi/cftb0246.pdf, preliminary 2009 data accessed November 09, 2010]. In addition, risks for occupational injury and illness have not been tracked; the relationships between occupational stress and physical exertion as well as chronic disease and mortality have not been adequately evaluated; and health and hazard surveillance systems have not been developed.
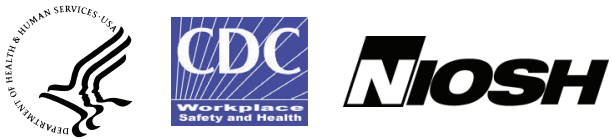

NORA 


\section{Overview of the Public Safety Sector Strategic Plan}

The NORA National Public Safety Sector Agenda is a strategic framework to ensure progress and track accomplishments through 2016 on priority occupational safety and health issues. The agenda includes sets of goals for four public safety industries, including law enforcement.

\section{Law Enforcement Strategic Goals}

\section{Evaluate existing information sources that may be enhanced or expanded to conduct occupational safety and health surveillance}

- Establish and evaluate model surveillance systems for exposure, illness, injury, and death

- Collect and evaluate information on exposures to chemical, physical, and biological agents associated with law enforcement activities

\section{Reduce traumatic injuries and fatalities from vehicle collisions by $15 \%$}

- Document, evaluate, and encourage the use of seat belts and alternative restraint systems

- Disseminate information on effective policies and practices that have been adopted to reduce law enforcement fatalities due to high-speed driving during pursuit or call response

\section{Reduce injury and death from criminal assaults by $10 \%$}

- Determine the frequency and nature of injury and death from criminal assaults

- Develop and disseminate materials that describe effective assault-related interventions

\section{Reduce cardiovascular disease disabilities and fatalities by $15 \%$}

- Determine the prevalence and occupational risk factors such as job classification, shift schedule, stress, and overtime

- Evaluate worksite medical appraisal and wellness programs, and then identify, develop, and disseminate effective program components
How You Can Help Improve the Safety and Health of Law Enforcement Workers

Your participation is needed to improve the safety and health of law enforcement employees at local, state, and federal agencies. The National Occupational Research Agenda (NORA) is seeking partners to achieve the goals outlined in its National Public Safety Sector Agenda. We invite you to participate in any of the following activities:

- Characterize exposures and report occupational safety and health hazards during law enforcement activities

- Assist in designing an effective system to track occupational illness, injury, and death

- Lead a workgroup to address a priority issue in one of the identified strategic goals

- Represent a partner organization to work on achieving a Public Safety Sector goal

- Advocate the use of implementation plans for goals at the local, state, and federal levels

- Provide input on implementing the identified goals to the point of contact identified below

- Suggest important occupational safety and health issues for law enforcement personnel to consider for future goals

\section{Contacts}

This fact sheet provides a synopsis of the Law Enforcement goals established by the NORA Public Safety Sector Council. To participate or to receive additional information please contact:

Bill Haskell

Public Safety Sector Coordinator

National Institute for Occupational Safety and Health (978) 470-1211·WHaskell@.cdc.gov

Kevin M. Sommers, Lieutenant, PEM

Emergency Management Coordinator

Warren, Michigan Police Department

Chairman, Safety and Technology Committee

Fraternal Order of Police

(586)634-4290・Ksommers@warrenpd.org

Please visit www.cdc.gov/niosh/nora/ for more information about NORA, the NORA Public Safety Sector, or to obtain the complete text of the National Public Safety Agenda. 